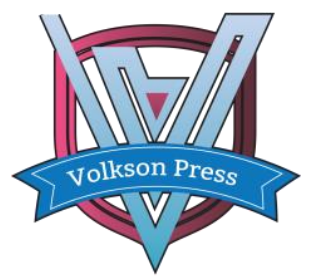

Contents List available at VOLKSON PRESS

Economics \& Management Innovations(EMI)

DOI : http://doi.org/10.26480/icemi.01.2017.226.228

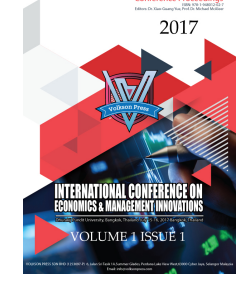

\title{
Is There Chaos in Inflation in China?
}

\author{
Chao Liu ${ }^{1,2}{ }^{*}$, Junhui Xu ${ }^{2}$, Yujie Ma ${ }^{2}$, Chao Wang 1,2 \\ ${ }^{1}$ School of Economics and Management, Beijing University of Technology, Beijing 100124, China \\ 2 Modern Manufacturing Industry Development Research Base of Beijing, Beijing 100124,China \\ *xtkx2011@163.com
}

This is an open access article distributed under the Creative Commons Attribution License, which permits unrestricted use, distribution, and reproduction in any medium, provided the original work is properly cited.

\section{ARTICLE DETAILS}

\section{Article History:}

Received 02 october 2017

Accepted 06 october 2017

Available online 11 october 2017

\section{Keywords:}

Inflation;

policy;

exponent.

\section{ABSTRACT}

Inflation is a permanent topic in macroeconomic field and an important issue related to social and political stability. Managing inflation expectations and easing inflationary pressures is also an important problem that macro-economy suffering in China recent years. Therefore, it is more critical to explore the internal operation mechanism of inflation to forecast and control it in essence.

Thus, based on system science finance theory, we use methods of correlation dimension and largest lyapunov exponent to examine the chaotic characteristic of inflation in China. The results show that the inflation system in China is chaotic, there are about two factors determining its operation, which reflects the complex operation mechanism of price in commodity markets ; the predictable time of inflation fluctuation tendency is approximately 11.29 months.

\section{Introduction}

Inflation is the main problem that China's current macroeconomic is facing [1]. Since the US subprime mortgage crisis has evolved into a global financial crisis in September 2008, China has been in a severe financial situation. As the typical developed countries in the international community, the United States has implemented a very loose monetary policy to deal with the global financial crisis, launching a inflation in the rise of the commodity prices and acceleration of the flow of hot money in China; China implemented expansionary fiscal policy and monetary policy in response to the global financial crisis in 2008, but it indirectly led to the rise of domestic price level [2]. Under the dual pressures of both domestic and foreign countries, inflation has been increasing since the second half of 2010, and CPI rose as high as $4.4 \%$ in October of the same year and maintained a high level of growth for a long time. Until February 2012, the phenomenon has been eased, but the CPI is still at a continuous level of growth, making the domestic price level rise, which is not conducive to the smooth operation of economy and society. In 2014, China's economy has entered a new normal status. Economic structure faces a major transformation. Economic development transformed from high-speed growth into high-speed growth. CPI year-on-year growth rate has declined. Also, low inflation has become a significant feature of "the new economic normal". But in December 2015, the dollar interest rates raised. The suppressed international commodity prices continue to go downward with a high probability and it is likely to result in Chinese input of deflation in the future. In addition, the country itself also needs to prevent too much excessive industrial capacity cut to make the industrial producer price index grow in a negative way and to make further transmission to the consumer price and the formation of deflation [3]. Therefore, in order to control the price increase within a reasonable range, to control the phenomenon of inflation effectively, to maintain the smooth operation of the economy, it is necessary to explore the internal operation of inflation mechanism and find the orderly rule of disorder. Our work lays theoretical basis for the regulation of monetary policy and improves the effectiveness of monetary policy.

\section{Literature Review}

Monetary policy is not only an important means of national macroeconomic regulation and control, but also an effective tool to maintain the stable development of social economy. It has always been a hot topic in the field of macroeconomic research. Price stability is one of goals of monetary policy, also the goal related to closely the people's lives, which affect stable operation of macro-economy and society directly, so government all over the world are committed to controlling inflation through monetary policy. As early as 1968 , Friedman studied relationship between money supply and inflation in the United States, finding that there was a positive correlation between money supply and inflation in the long term [4]. Then, Poole's study found the coordinated relationship between inflation and economic growth as well as financial stability, which is exactly the embodiment of the relationship between inflation and multitargets of monetary policy [5]. Mishkin believed that the implementation of an independent monetary policy of the central bank was almost all flexible inflation targeting system [6]. El-Shagi and other scholars studied the relationship between monetary policy and inflation in the background of the monetary policy of different countries [7-9]. Based on these studies, Wang et al. analyzed Chinese monetary policy tools and targeted system through Granger causality test and impulse response analysis, and found that narrow money supply is the most effective intermediate target of Chinese inflation [10]. Furthermore, Zhang et al. suggested that adjustment of monetary policy must take persistence and the inherent nonlinear characteristics of inflation into account as much as possible [11] The implementation of monetary policy and inflation are closely related, which is the main topic of national monetary policy. There is complex operating mechanism affected by many factors inside. Considering current relevant research, however, we found that most of researches lies in theory of inflation and transmission mechanism, but the less studies of inflation's internal operating mechanism is not enough to systematically explain fluctuation and uncertainty of inflation. Therefore, the paper innovatively adopt small data volume algorithm that suitable for macroeconomic market to calculate largest lyapunov exponent, to test chaotic characteristics of inflation in China in quantitative form and explore the incentive of inflation under the chaotic characteristics and determine its predictable time so as to predict it more accurately on the basis of the evolution of the internal mechanism of inflation.

\section{Empirical Test of Chaotic Characteristic of inflation in China}

\subsection{Data description and processing}

When the price of most goods and services continues to rise for some time, that is inflation in macroeconomics. It can be seen that inflation measures the rise of overall price level, and the overall price level or general price level refers to the weighted average of the total price of all goods and services, that is, the price index. Thus, academia generally defines inflation as following formula: 


$$
\text { Inflation_Rate }=\left(C P I_{1}-C P I_{0}\right) / C P I_{0}
$$

$C P I_{1}$ measures current price level and $C P I_{0}$ reflects the base price level.

Based on the above formula, we choose CPI monthly data from 1997 to 2016, all data are from the National Bureau of Statistics official website. And then calculate inflation rate based on the above formula. According to results of ADF unit root test and normality test, we can find that inflation rate time series is stable in $99 \%$ confidence interval, as well as, shows a non-normality, and we can test the chaotic characteristic of inflation further.

\subsection{The Chaos Test of Inflation}

\subsubsection{Auto-correlation Function Method for Time Delay}

Based on the theory basis of autocorrelation function method, reconstruct phase space of inflation rate time series. The diagram of time delay is shown in Fig.1.

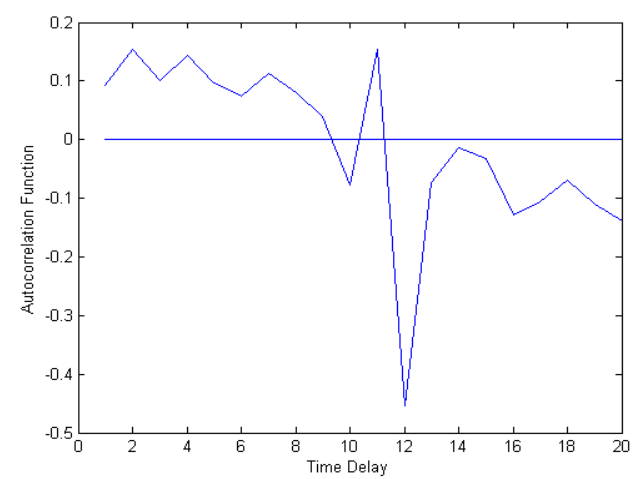

Fig. 1. Time delay of inflation rate

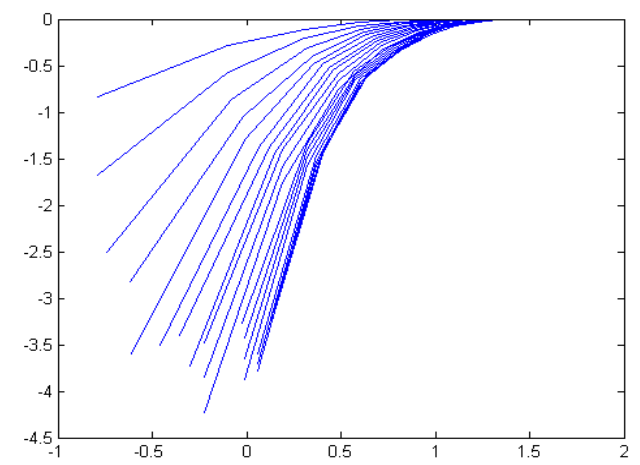

Fig. 2. Lnc-Inr relationship of inflation rate

In the empirical study, the first zero point that the autocorrelation function $\mathrm{C}(\tau)$ cross is usually chosen as the time delay $\tau$. As can be seen from Fig. 1 , when the time delay $\tau$ of inflation rate equal to 9 , the autocorrelation functions $C(\tau)$ cross 0 point for the first time. The time delay of phase space reconstruction of inflation rate is 9 .

\subsubsection{G-P Algorithm for Correlation Dimension}

The correlation dimension is an important index to judge the complexity of the system. Whether the correlation dimension can be saturated is the basis for inferring whether the inflation correlation time series is chaotic. If the correlation dimension increases with the increase of the embedded dimension, then the time series is random and not chaotic. If the correlation dimension is saturated with the increase of the embedded dimension, it can be explained that the time series are chaotic.

By using G-P algorithm, we calculate the correlation dimension of inflation rate by matlab to get lnc-lnr relationship diagram. And then adopt linear fitting with straight part. When the correlation dimension reaches saturation, the correlation dimension of inflation is obtained. The results are shown in Fig. 2, Fig. 3 and Table 1.

Fig. 2 shows the lnc-lnr relationship of correlation dimension of sequence as the embedding dimension increases from 1 to 20 . It can be seen that the lnc-lnr curve gradually coincides as increasing of embedding dimension.
So we can deduce that the correlation dimension of inflation rate reaches a saturation value with the increase of embedding dimension. Table 1 and Fig. 3 are the estimation of correlation dimension and convergence graph for inflation rate respectively. And Fig. 3 is more intuitive representation of correlation dimension estimation in Table 1.

Table 1. Estimation of correlation dimension and embedding dimension of inflation rate

\begin{tabular}{|l|l|l|l|l|l|l|l|l|l|l|}
\hline $\mathbf{m}$ & $\mathbf{1}$ & $\mathbf{2}$ & $\mathbf{3}$ & $\mathbf{4}$ & $\mathbf{5}$ & $\mathbf{6}$ & $\mathbf{7}$ & $\mathbf{8}$ & $\mathbf{9}$ & $\underline{\mathbf{1 0}}$ \\
\hline $\mathrm{D}($ & 0.3 & 0.6 & 0.9 & 1.1 & 1.4 & 1.5 & 1.5 & 1.7 & 1.7 & $\underline{1.9}$ \\
$\mathrm{~m}$ & 17 & 37 & 68 & 60 & 73 & 46 & 77 & 52 & 16 & $\underline{\mathbf{0 4}}$ \\
$\mathrm{j}$ & 6 & 3 & 7 & 6 & 9 & & 3 & 8 & 2 & $\underline{\mathbf{2}}$ \\
\hline $\mathrm{m}$ & 11 & 12 & 13 & 14 & 15 & 16 & 17 & 18 & 19 & 20 \\
\hline $\mathrm{D}($ & 2.1 & 1.7 & 1.8 & 2.0 & 2.1 & 2.0 & 2.1 & 2.1 & 1.9 & 1.9 \\
$\mathrm{~m}$ & 02 & 95 & 84 & 08 & 25 & 62 & 34 & 80 & 55 & 80 \\
$\mathrm{D}$ & 7 & & 8 & 1 & 6 & 1 & 1 & 7 & 2 & 6 \\
\hline
\end{tabular}

Note: $D(m)$ is value of correlation dimension of inflation rate, and $m$ is value of embedding dimension, and value underlined is convergence value of correlation dimension and its corresponding embedding dimension. The above results are analyzed as follows:

a) The operation of inflation in China is chaotic. With increasing of embedded dimension $\mathrm{m}$, correlation dimension $\mathrm{D}(\mathrm{m})$ of inflation rate gradually increases, and finally converges to 1.9042, which proves the conclusion in Fig. 2, and it can be initially inferred that inflation is chaotic.

b) Correlation dimension of inflation rate reached saturation value of 1.9042, which means that the fractal dimension of chaotic attractor of inflation rate sequence is about 1.9042 . At this time, the embedded dimension $\mathrm{m}$ is 10 , which indicates that there are about ten factors influencing the change of inflation, including macroeconomic factors, international commodity prices, monetary policy and so on [12]. But there are two long-term decisive factors determine inflation changes together.

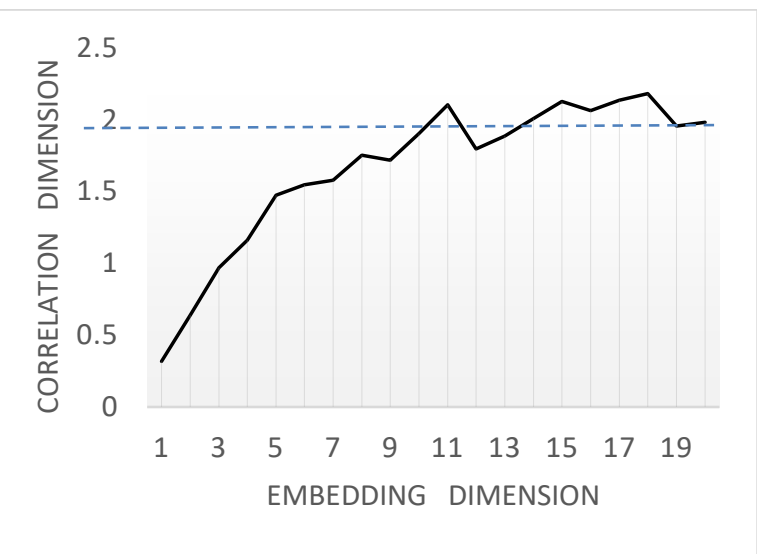

Fig. 3. Convergence diagram of correlation of inflation rate

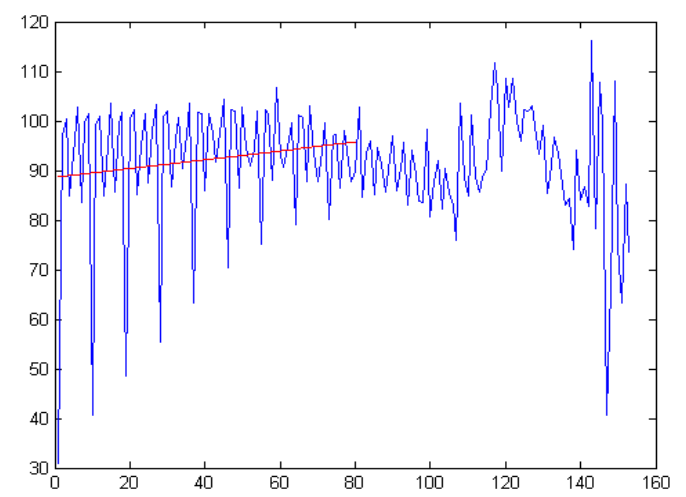

Fig. 4. Largest lyapunov exponent dimension of inflation rate

\subsubsection{Calculation of Largest Lyapunov Exponent}


Correlation dimension reflects chaotic characteristics of inflation approximately. In order to determine chaos of inflation more accurately, it is necessary to calculate largest lyapunov exponent. If the largest lyapunov exponent is larger than zero, it can accurately show that Chinese inflation is chaotic. In view of limited amount of macroeconomic data, this study uses the small data volume method to calculate the largest lyapunov exponent. The results show that the time delay of inflation rate is 9, the spatial embedding dimensions is 10 and the mean period is 3.5821 by fast fourier transform (FFT). We plug these parameters into the small data volume algorithm program and finally get its largest lyapunov exponent equivalent to 0.0886. The slope of the straight line in Fig. 4 is the estimation value of the largest lyapunov exponent of inflaton rate.

Chinese inflation has chaotic characteristics. The largest lyapunov exponent of inflation rate is larger than zero, indicating that inflation system contains chaotic attractors. Further, in view of chaos in inflation, its evolution rule is sensitive to initial condition and, consequently, it can only be short-term predicted, besides, it will lose ability of predicting system evolution at an average rate of 0.0886 bits per month. Moreover, the reciprocal of largest lyapunov exponent represents time scale that the system can predict, so that the predictable time for inflation is about 11.29 months. So that the trend of the indicator can be used to predict whether inflation occurs in our country and degree of inflation, then make relevant policies in order to control the inflation.

\section{Conclusions}

Based on the nonlinear financial theory, this paper takes inflation rate which reflecting price fluctuation as research object, and uses small data volume method to study chaos of inflation in China. The conclusions are as follows: a) Chinese inflation system is a complex nonlinear lowdimensional chaotic system. There are 10 factors influencing the evolution of system and 2 essential factors which play a decisive role in operation of inflation system evolution. b) In view of chaotic characteristic of inflation system, it is possible to make short-term prediction. The predictable time of inflation is 11.29 months, so that the authorities could take precautionary measures in advance to control risks by measuring extent of inflation in short-term future.

Combined with the results above, the following policy recommendations are proposed:

a) Intervene targets reasonably and conduct market effectively. For the sake of further controlling the degree of inflation, the government should correctly understand the chaotic characteristics of inflation and conduct reasonable market intervention to Chinese trading market. From chaos of inflation, we can see that there are two main factors influencing Chinese inflation. Therefore, we should further explore its deterministic factors, and then determine reasonable intervention goal and improve the effectiveness of market intervention.

b) Make forecasts for Chinese inflation accurately. It is an effective way to control inflation by forecasting inflation trends and then adjusting monetary policy based on forecasted trends. Chinese inflation has chaotic characteristics, and we can only make shortterm forecast. Therefore, we should make forecast in foreseeable time. The forecast beyond predictable time will have a negative impact on effectiveness of monetary policy implementation.

\section{References}

[1] F.P. Peng, Y.J. Lian and H.M. Zhao: Economic Growth and Inflation Tolerance in China: Empirical Evidence from Firm Level. Financial Research. (2013), p. 87-100.

[2] Q.Y. Zhang: Research on the Effectiveness of Monetary Policy in the Perspective of CPI. Journal of Jilin Finance Research. (2012), p. 1-10.

[3] Information

http://www.cet.com.cn/ycpd/sdyd/1399622.shtml.

[4] M. Friedman: The Role of Monetary Policy. American Economic Review. Forum Vol. 58 (1968), p. 75.

[5] W. Poole: Inflation, Financial Stability and Economic Growth (2007).

[6] F. S. Mishkin: Monetary Policy Strategy: Lessons from the Crisis (2007)

[7] M. El-Shagi and S. Giesen: Money and Inflation: Consequences of the Recent Monetary Policy. Journal of Policy Modeling. Forum Vol. 35 (2013), p. 520-537.

[8] R. Bhattacharya: Inflation Dynamics and Monetary Policy Transmission in Vietnam and Emerging Asia. Journal of Asian Economics. Forum Vol. 13 (2014), p. 16-26.

[9] A. Christev and K. Yue: Money and Inflation: Is Monetary Policy Useful? Manchester School. Forum Vol. 83 (2015), p. 30-50..

[10] X. Wang, W. L. Zou and M. Ye: The Choice of Monetary Policy Implemental Procedure to Curb Inflation in China. China Industrial Economics (2012), p. 5-17.

[11] Q. Y. Zhang, W. P. Guo and H. B. Miao: Persistence of Inflation and Its Monetary Policy Implications in the Euro Area. International Finance Research (2015), p.77-86.

[12] Q. B. Meng, X. T. Jin and L. Wu: On the Non-linear Effects of the Affecting Factors on Inflation in China (2014), p. 30-46. 